\title{
BMJ Open The opportunity of patient-journey studies for academic clinical research in oncology
}

\author{
Francesco Perrone (D) , ${ }^{1}$ Raimondo Di Liello (D) , ${ }^{1}$ Piera Gargiulo, ${ }^{1}$ Laura Arenare, ${ }^{1}$ \\ Lorenzo Guizzaro, ${ }^{2,3}$ Paolo Chiodini (1) ,2 Ciro Gallo (D) ,', Maria Carmela Piccirillo ${ }^{1}$
}

To cite: Perrone F, Di Liello R, Gargiulo P, et al. The opportunity of patient-journey studies for academic clinical research in oncology. BMJ Open 2021;11:e052871. doi:10.1136/ bmjopen-2021-052871

- Prepublication history and additional supplemental material for this paper are available online. To view these files, please visit the journal online (http://dx.doi.org/10.1136/ bmjopen-2021-052871)

Received 27 April 2021 Accepted 09 September 2021

Check for updates

(c) Author(s) (or their employer(s)) 2021. Re-use permitted under CC BY-NC. No commercial re-use. See rights and permissions. Published by BMJ.

${ }^{1}$ Clinical Trial Unit, Istituto Nazionale Tumori IRCCS

Fondazione Pascale, Napoli, Italy

${ }^{2}$ Medical Statistics Unit, Università degli Studi della Campania Luigi Vanvitelli, Napoli, Italy

${ }^{3}$ Human Medicines, European Medicines Agency, Amsterdam, Netherlands

Correspondence to

Dr Francesco Perrone;

f.perrone@istitutotumori.na.it

\section{ABSTRACT}

A wave of new treatments and treatment combinations are becoming available for solid tumours. Trials performed to obtain registration establish a positive benefit-risk but unavoidably leave many questions unanswered on placein-therapy and the relative efficacy of different treatment sequences. Such limitations create problems in terms of strength of treatment guidelines and reimbursement (in countries where a public payer exists). Data on new drugs arriving during the last 10 years for the treatment of hepatocellular carcinoma and renal cancer are reported as an example of how the fortunate condition of having new effective treatments may translate into uncertainty regarding the optimal treatment plan. We suggest that academic research should react to such limitations and propose a model of patient-journey study (PJS), where patients are followed from the initial diagnosis across subsequent lines of treatment. A PJS master protocol might include at each node of clinical decision either the possibility of choosing treatment according to guidelines (generating prospective real-world evidence) or the possibility to randomise where uncertainty exists (generating comparative effectiveness data). PJS protocols might be adaptively modified every time a new drug arrives on the market. Overall, methodologically sound analyses of PJS will produce knowledge on the efficacy and the effectiveness of different treatment pathways and might significantly optimise treatment of patients in clinical practice. PJS would represent a jump from a few snapshots (trials performed to get regulatory approval) to a full movie (evidence on the relative value of treatment pathways).

\section{INTRODUCTION}

Oncology is living along contrasting trajectories. As knowledge on molecular causes and drivers of cancer growth increases, a large part of the scientific community tries to translate it into therapeutic options; notwithstanding such efforts, precision oncology is not yet established as an effective strategy beyond any reasonable doubt. On the other side, a wave of combination of immune checkpoint inhibitors with other new or old drugs is showing to be effective in several settings. ${ }^{1}$ This is a fortunate situation, because it is much better to have several therapeutic options than none or very few. Figure 1 shows, for example, how the number of available treatments (detailed in the online supplemental table 1) has rapidly expanded within the last 10 years for hepatocellular carcinoma (HCC) and renal cell carcinoma (RCC), two types of cancers characterised in the past by the availability of few or very few therapeutic options.

\section{Introducing new drugs into market}

Pharmaceutical industries drive the arrival of new drugs to the market, often building on academic research discovering new therapeutic mechanisms and treatment strategies. The system might be virtuous, but unfortunately it is suffering a severe shortness of breath. More and more problems derive from the rising cost of new drugs. ${ }^{2}$ Problems also arise from limitations of clinical trials designed to obtain regulatory approval. ${ }^{3} 4$ Such trials, indeed, are snapshots on the efficacy of new drugs. As a consequence, what comes before (eg, characteristics of eligible patients and acceptability of the comparator treatment) might be no longer consistent with clinical practice when the drug arrives to the market. And, what comes after the snapshot (eg, outcome after subsequent lines of treatment) is by design excluded from what the trials are able to robustly characterise.

\section{Introducing new drugs into clinical practice}

Therefore, the place-in-therapy of some new drugs is far from being clear when they arrive to the market, and the wave of innovation might turn into chaos, causing both unsustainability and confusion of scientific evidence, resulting in an inability to identify and address the needs of patients. To find the best treatment algorithm in HCC and RCC, for example, is becoming complex due to shortcomings of available evidence (see ESMO guidelines at https://www.esmo. org/guidelines/gastrointestinal-cancers/ 


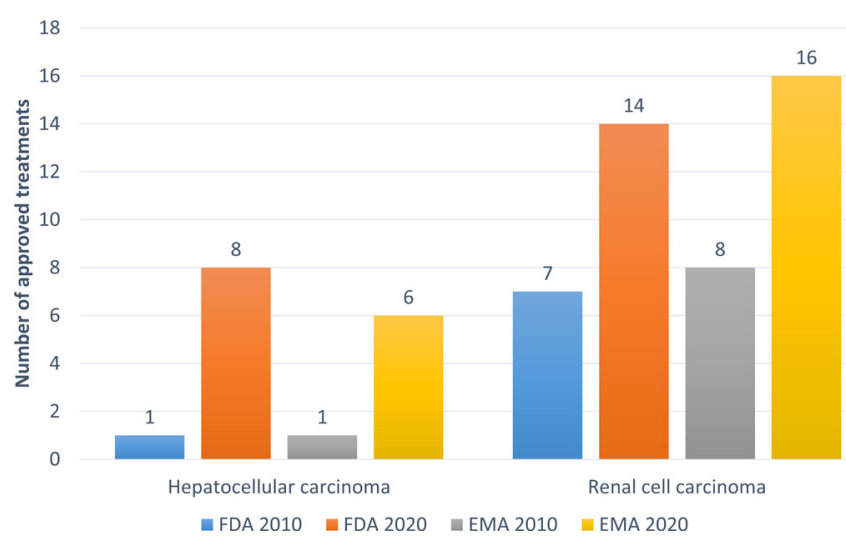

Figure 1 Treatments approved by the FDA and EMA for hepatocellular carcinoma and renal cell cancer in 2010 and 2020. EMA: European Medicines Agency; FDA: US Food and Drug Administration.

hepatocellular-carcinoma/eupdate-hepatocellular-carcinoma-treatment-recommendations and https://www. esmo.org/guidelines/genitourinary-cancers/renal-cellcarcinoma/eupdate-renal-cell-carcinoma-treatmentrecommendations-3). New drug combinations, indeed, are being approved because proved better than the same drug that was standard when trials were planned (sorafenib in HCC and sunitinib in RCC). ${ }^{5}{ }^{6}$ Nevertheless, nobody knows the relative efficacy of such combinations (lacking head-to-head trials) or which is the best treatment sequence where multiple options exist that can be used at different stages of the disease (lacking clinical trials comparing different treatment sequences). Consequently, decisions of all stakeholders that come after regulatory approval are made more difficult.

\section{Moving from the snapshot to the movie}

We propose that academy, in collaboration with patient organisations, should react implementing a research strategy focused on the therapeutic pathways of patients (patient-journey study (PJS)) rather than on the efficacy of single treatments. A PJS might enrol patients at diagnosis and follow them across subsequent lines of treatment. At each treatment-decision node, within a desirable framework of shared decision-making, ${ }^{7}$ to the patient would be offered the option to choose according to guidelines, randomise where uncertainty exists (according to a formal protocol with its own study design) or access to other trials (regardless of phase and sponsor) when available and reasonable. Therefore, the master protocol of a PJS will prospectively integrate trials and real-world evidence, overcoming the existing dualism and favouring the quality of both. ${ }^{8}$ It will empower shared decision-making and might be inclusive for biomarker studies and precision oncology trials, loco-regional treatments, supportive care and pharmaco-economic analyses. In countries where public coverage of cancer drug exists, knowledge generated through appropriate analyses of such studies might allow to implement reimbursement according to the model of coverage with evidence development. ${ }^{9}$ Globally, it might be useful to strengthen the evidence base for international guidelines, frequently self-limiting to a listing approach, being unable to select which options are the best. Particularly, a PJS might be instrumental to describe and value how patients' preferences might usefully be considered and reflected in developing or updating guidelines. ${ }^{1011}$

Overall, such research strategy might be a way for moving from a few snapshots to a full movie, that moght also open new chances for on-stage photographers. ${ }^{12}$

Correction notice This article has been corrected since it first published. The disclaimer statement has been included.

Twitter Francesco Perrone @fperrone62

Contributors FP, CG and MCP conceived and designed the study. RDL and PG performed bibliographic research and acquired data. FP, RDL, PG, LA, LG, PC, CG and MCP wrote the manuscript.

Funding The authors have not declared a specific grant for this research from any funding agency in the public, commercial or not-for-profit sectors.

Disclaimer The views expressed in this article are the personal views of the authors and may not be understood or quoted as being made on behalf of or reflecting the position of the agencies or organisations with which the authors are affiliated.

Competing interests FP reports grants, personal fees and non-financial support from Bayer, personal fees from Sandoz, grants and personal fees from Incyte, personal fees from Celgene, grants and personal fees from AstraZeneca, personal fees from Pierre Fabre, personal fees from Janssen Cilag, grants from Roche and grants from Pfizer, outside the submitted work. RDL reports personal fees from Astellas, outside the submitted work. CG reports personal fees from AstraZeneca, outside the submitted work. MCP reports personal fees from Daichii Sankyo, personal fees from GSK, personal fees from MSD, grants from Roche, grants and personal fees from AstraZeneca and non-financial support from Bayer, outside the submitted work. The other authors do not declare conflicts of interests.

Patient consent for publication Not required.

Provenance and peer review Not commissioned; externally peer reviewed.

Supplemental material This content has been supplied by the author(s). It has not been vetted by BMJ Publishing Group Limited (BMJ) and may not have been peer-reviewed. Any opinions or recommendations discussed are solely those of the author(s) and are not endorsed by BMJ. BMJ disclaims all liability and responsibility arising from any reliance placed on the content. Where the content includes any translated material, BMJ does not warrant the accuracy and reliability of the translations (including but not limited to local regulations, clinical guidelines, terminology, drug names and drug dosages), and is not responsible for any error and/or omissions arising from translation and adaptation or otherwise.

Open access This is an open access article distributed in accordance with the Creative Commons Attribution Non Commercial (CC BY-NC 4.0) license, which permits others to distribute, remix, adapt, build upon this work non-commercially, and license their derivative works on different terms, provided the original work is properly cited, appropriate credit is given, any changes made indicated, and the use is non-commercial. See: http://creativecommons.org/licenses/by-nc/4.0/.

\section{ORCID iDs}

Francesco Perrone http://orcid.org/0000-0002-9738-0526

Raimondo Di Liello http://orcid.org/0000-0003-4511-7969

Paolo Chiodini http://orcid.org/0000-0003-0139-2264

Ciro Gallo http://orcid.org/0000-0002-7939-3104

\section{REFERENCES}

1 Tan AC, Bagley SJ, Wen PY, et al. Systematic review of combinations of targeted or immunotherapy in advanced solid tumors. J Immunother Cancer 2021;9:e002459.

2 Ramsey SD, Lyman GH, Bangs R. Addressing skyrocketing cancer drug prices comes with tradeoffs: Pick your poison. JAMA Oncol 2016;2:425-6. 
3 Hilal T, Gonzalez-Velez M, Prasad V. Limitations in clinical trials leading to anticancer drug approvals by the US food and drug administration. JAMA Intern Med 2020;180:1108-15.

4 Naci H, Davis C, Savović J, et al. Design characteristics, risk of bias, and reporting of randomised controlled trials supporting approvals of cancer drugs by European medicines Agency, 2014-16: cross sectional analysis. BMJ 2019;366:I5221.

5 Gordan JD, Kennedy EB, Abou-Alfa GK, et al. Systemic therapy for advanced hepatocellular carcinoma: ASCO guideline. J Clin Oncol 2020;38:4317-45.

6 Powles T, ESMO Guidelines Committee. Electronic address: clinicalguidelines@esmo.org. Recent eUpdate to the ESMO clinical practice guidelines on renal cell carcinoma on cabozantinib and nivolumab for first-line clear cell renal cancer: renal cell carcinoma: ESMO clinical practice guidelines for diagnosis, treatment and follow-up. Ann Oncol 2021;32:422-3.

7 Josfeld L, Keinki C, Pammer C, et al. Cancer patients' perspective on shared decision-making and decision AIDS in oncology. J Cancer Res Clin Oncol 2021;147:1725-32.
8 Di Maio M, Perrone F, Conte P. Real-World evidence in oncology: opportunities and limitations. Oncologist 2020;25:e746-52.

9 Antonanzas F, Juárez-Castelló C, Lorente R, et al. The use of risk-sharing contracts in healthcare: theoretical and empirical assessments. Pharmacoeconomics 2019;37: 1469-83

10 Gärtner FR, Portielje JE, Langendam M, et al. Role of patient preferences in clinical practice guidelines: a multiple methods study using guidelines from oncology as a case. BMJ Open 2019:9:e032483.

11 Wieringa S, Dreesens D, Forland F, et al. Different knowledge, different styles of Reasoning: a challenge for Guideline development. BMJ Evid Based Med 2018;23:87-91.

12 Perrone F. From snapshots to a movie. challenging the patterns of academic research. Recenti Prog Med 2021;112:

97-9. 